\title{
A COMUNIDADE EDUCATIVA E O TRABALHO COM VALORES SOCIOMORAIS: DOIS ESTUDOS DE CASO - UMA ESCOLA COOPERATIVA E UMA REDE MUNICIPAL
}

\author{
MARILUCIA MORAES DE PAULA FERREIRA* \\ ANA MARIA FALCÃO DE ARAGÃO**
}

\begin{abstract}
RESUMO
Neste trabalho, o olhar para a Educação se dá tendo por base a convivência ética e democrática nas escolas e a educação de valores sociomorais, os conflitos interpessoais como oportunidade de aprendizagem e a gestão cooperativa como mediadora em prol do desenvolvimento moral da comunidade educativa. Para investigar como a escola legitima as ações e as decisões coletivas, já previstas em uma gestão democrática, visando ao bem comum, é importante destacar que foram realizados dois estudos de caso. O primeiro foi efetuado a partir de um projeto de formação em uma escola cooperativa e o outro, em uma rede municipal. Destacamos que o primeiro foi demandado por meio do seguinte relato: "A escola apresenta algumas situações preocupantes: 1. Equipe de profissionais e os membros da mantenedora estão divididos em dois grupos, percebendo-se uma ruptura, pensamentos divergentes que levam a mal-entendidos e procedimentos inadequados, como consequência da falta de um elo para direcionar as decisões. 2. Não há cooperação do grupo, em virtude da falta de harmonia conceitual, pois a escola possui uma gestão democrática. Enfim, torna-se necessário ter o apoio de
\end{abstract}

* Aluna do Programa de Pós-Graduação em Educação - UNICAMP; MF Educacional-marilucia@mfeducacional.com.br - http://lattes.cnpq. br/7156037171088060

** Professora doutora, titular - Universidade Estadual de Campinas - SP Brasil - anaragao@unicamp.br - http://lattes.cnpq.br/0078129824340671 
um profissional externo para alinhar ações, a fim de que a escola caminhe com segurança, para se resgatar a cultura participativa". No segundo projeto, a necessidade detectada foi identificar os princípios democráticos da escola, para sustentar a elaboração do Projeto de Convivência Ética de uma rede pública municipal, cujo objetivo foi revelar os procedimentos de que o gestor dispõe, a fim de se chegar a um projeto de escola que seja político, isto é, participativo e dialógico, por meio do Projeto Convivência Ética. Antes de desenvolver um trabalho é necessário alinhar os aspectos procedimentais previstos nos documentos da instituição, sendo essencial superar o modus operandi da escola, sedimentado já há muitos anos, problematizando o entendimento do conceito de valor. Já na rede pública municipal, o objetivo foi promover a discussão acerca do Plano de Convivência Ética nas escolas aliado ao seu Projeto Político-Pedagógico. Os valores, os princípios e as regras eram discutidos, para que se estabelecesse uma relação com os projetos das escolas, de sorte a instrumentalizar a gestão na direção de um fazer democrático. Finaliza-se, apontando que o intuito das autoras é apresentar evidências de que só é possível que os sujeitos validem e legitimem os projetos e as ações na escola, se vivenciarem os conceitos em questão.

Palavras-chave: valores. Convivência ética. Gestão democrática.

\title{
INTRODUÇÃO
}

\author{
Como podemos formar moralmente \\ nossas crianças e adolescentes, se não \\ temos espaços para essa formação ou, então, \\ não validamos esses momentos de conflitos \\ como oportunidade de formar eticamente \\ nossos alunos? (TOGNETTA, 2009, p. 13).
}

A formação de personalidades éticas não ocorre por transmissão direta, nem é decorrente de um desenvolvimento ma- 
turacional, mas, sim, de um processo de construção nas interações do sujeito com o meio. Para que esse desenvolvimento aconteça são necessárias experiências morais. Por exemplo, não se aprende sobre ética, diálogo e valores apenas com discursos ou teorizações sobre o assunto, mas experimentando relações cooperativas nas quais o conflito é a possibilidade de aprender a olhar, pontuando diferentes perspectivas, para conhecer a si e ao outro, bem como identificando valores da comunidade em que estão inseridos.

Baseadas nessa premissa, realizamos dois projetos: em uma escola cooperativa e em uma rede pública municipal. $\mathrm{Na}$ primeira instituição onde o trabalho foi concretizado, algumas situações preocupantes foram detectadas; entre elas, vimos que não havia cooperação do grupo, em virtude da falta de harmonia conceitual, pois a escola declarava em seus documentos uma gestão democrática e não havia registro de espaços de diálogo. Assim, para esclarecer valores, foi preciso organizar um grupo de estudos, de modo que a escola caminhasse com segurança e coerência e pudesse resgatar a cultura participativa.

No segundo estudo, implementamos a formação mensal e remota de um grupo de gestores de uma rede pública municipal do interior de São Paulo com o objetivo de promover a discussão acerca do Plano de Convivência Ética na escola aliado ao seu Projeto Político-Pedagógico. Os valores, os princípios e as regras eram discutidos, a fim de que se estabelecesse uma relação com os projetos das escolas, buscando instrumentalizar a gestão na direção de um fazer democrático. Para isso, é importante que se consiga o entendimento dos conflitos interpessoais, dos valores e da justiça que sustentam o Regimento Escolar. Por conseguinte, defendemos a necessidade de um entendimento, para que essas dimensões sejam ressignificadas e possam favorecer a construção do sentido e, consequentemente, de uma lógica que embase os encaminhamentos e as tomadas de decisão pela comunidade educativa, tais como os procedimentos perante desavenças, além 
de justiça que restaure relações e sanções, favorecendo, portanto, o respeito e a solidariedade.

Araújo, Puig e Arantes (2007) afirmam que a cultura moral é uma forma onipresente de educação em valores e, portanto, seu instrumento mais efetivo. Os autores também ressaltam que "[...] a totalidade da instituição é uma poderosa força educativa que incide sem cessar na formação pessoal dos alunos (p. 94).”

\section{CAMINHOS TRILHADOS NOS PROJETOS EM TELA}

No intuito de se buscar dados acerca da realidade da primeira escola foram lidos todos os documentos institucionais (Estatuto, Regimento Escolar, Projeto Político-Pedagógico) e agendadas reuniões individuais com a mantenedora e com cada membro do núcleo diretivo. Com base nos dados obtidos em documentos e entrevistas, o contexto da escola foi revelado, apontando as fragilidades e pistas para a revisão do Plano de Gestão e do Regimento Escolar.

Destarte, a fim de que fosse possível promover a construção de uma gestão e de uma educação democrática foi necessário investir na formação humana pautada em valores sociomorais, o que poderia influenciar para além do âmbito escolar e contribuir na construção de relações solidárias, em nossa sociedade, diferentemente dos valores capitalistas.

Conforme Araújo, Puig e Arantes (2007), esse processo de embeber-se em valores e convertê-los em hábitos e atitudes depende da capacidade da instituição de vivenciar realmente os valores defendidos. Por isso, a atmosfera do centro educativo nos impregna como que por osmose, quando mergulhamos em sua realidade; a cultura moral é uma forma onipresente de educação em valores e, logo, seu instrumento mais efetivo.

Antes de desenvolver um trabalho para atualizar e alinhar aspectos procedimentais previstos nos documentos da instituição foi essencial superar o modus operandi da escola, sedimentado já há muitos anos, problematizando o entendimento conceitual de valor - o que valorizamos, em nossa escola? 
De acordo com Vasquez (1993) valores são atribuições realizadas por sujeitos sociais sobre propriedades de objetos, sejam estes naturais, sejam produtos humanos. Ao valorizar algo, o sujeito o faz a partir de elementos de sua cultura.

Posto isso, a intervenção na escola pautou-se, pois, em ações que pudessem contribuir para que a equipe de profissionais reconhecesse quais valores estavam de fato presentes no trabalho da escola e quais aqueles que deveriam ser procurados, assim como a coerência entre os documentos oficiais da instituição e o trabalho por ela desenvolvido. Nessa perspectiva, foi estabelecido um Plano de Trabalho contemplando duas etapas: a primeira - estudos para a compreensão de conceitos necessários para a análise da realidade da escola: valores e conflitos; a segunda análise e recondução dos processos desenvolvidos na escola.

Com base nos pressupostos da formação para a autonomia e de uma convivência ética, questionamos: de que maneira os instrumentos organizacionais da escola, conhecidos como documentos oficiais, poderiam contribuir para que a convivência diária nesse ambiente se tornasse uma realidade intencionalmente planejada e pautada em princípios sociomorais? Inferimos que a qualidade das relações, ou seja, o modo de ser e viver da escola, é um dos elementos da gestão que revela a cultura moral da instituição.

\section{COMO O TRABALHO FORMATIVO FOI REALIZADO?}

$\mathrm{Na}$ escola cooperativa, assim como na rede municipal, os participantes do estudo conheceram a estrutura do Projeto Político-Pedagógico (PPP): Marcos Referenciais - Diagnóstico - Programação (Plano de ação), segundo o modelo apresentado pela Equipe Latino-Americana de Planejamento (ELAP), com sede no Chile, na vertente brasileira do prof. Danilo Gandin (apud VASCONCELLOS, 2012, p. 170):

Marcos Referenciais: refere-se ao que a escola quer alcançar. É a busca de um posicionamento, visão do ideal de 
sociedade e de homem; definição sobre a ação educativa e sobre as características que deve ter a instituição que planeja.

Diagnóstico: O que falta para ser o que desejam. É a busca das necessidades, a partir da análise da realidade e/ou do juízo sobre a realidade da instituição (comparação com aquilo que desejamos que seja).

Programação: $O$ que faremos concretamente para suprir tal falta? É a proposta de ação. O que é necessário e possível para diminuir a distância entre o que vem sendo a instituição e o que deveria ser.

Depois das análises das informações na estrutura do PPP da escola apresentada pela formadora, identificaram-se os conceitos que sustentam o Plano de Convivência: valores, conflitos, regras e sanções para que localizassem em seus documentos e no que está previsto na LDB e no projeto na escola.

\section{$1^{\circ}$ CASO - O TRABALHO NA ESCOLA COOPERATIVA:}

As dez reuniões de estudo foram planejadas com duração de quatro horas, totalizando 40 horas, com os seguintes objetivos:

- Estudar a necessidade das normas e os procedimentos de legitimação que devem preservar os valores institucionais para uma convivência respeitosa e justa;

- Compreender a adesão de valores realizada pelas pessoas, na convivência diária;

- Partilha coletiva: valores de cada um e os valores de sempre: o que pensava... o que penso;

- Ler trechos destacados do PPP e Plano de Gestão;

- Identificar o que é valor, para a escola;

- Retomar e verbalizar os conceitos: conflitos e valores;

- Apresentar os valores contidos nos documentos da escola;

- Escolher os valores;

- Identificar e diferenciar as informações contidas no PPP e no Plano de Gestão; 
- Conhecer a estrutura do Projeto Político-Pedagógico (VASCONCELLOS E GANDIN);

- Organizar das informações contidas nos dois planos: PPP e Plano de Gestão da escola;

- Analisar o grau de instalação dos descritores referentes ao núcleo diretivo;

- Comparar os descritores institucionais e os propostos pela Fundação Chile.

Após identificação dos valores à luz dos princípios institucionais procedeu-se à análise das ações descritas para os cargos/funções e os devidos aprimoramentos e atualizações dos procedimentos educativos. Finalizamos o trabalho com um Plano de Ações.

\section{O QUE DISSERAM OS GESTORES: EXEMPLOS DE DADOS}

Relato: - O trabalho de assessoria da MF Educacional, em nossa escola, uma instituição com perfil de gestão altamente democrática, oportunizou o engajamento de toda a comunidade escolar na organização da estrutura do trabalho pedagógico: as funcões (tanto de colaboradores quanto das familias) foram claramente definidas, o que favoreceu a otimização dos procedimentos internos. Tivemos auxilio para definir objetivos e traçar metas da Instituição. (Núcleo Diretivo e Mantenedores da escola 1).

\section{$2^{\circ}$ CASO: O PROJETO FORMATIVO TEVE OS SEGUINTES OBJETIVOS:}

- Aproximar o ideal de convivência respeitosa e justa com a prática cotidiana;

- Entender a estrutura do PPP, de sorte a sustentar a identidade, autonomia moral e intelectual da instituição;

- Inserir no PPP os conceitos e procedimentos contidos no Plano de Convivência. 


\section{Participantes:}

Estiveram reunidos em dois grupos:

- 37 Diretores da Educação Infantil ao Ensino Médio - rede pública municipal

- 23 Diretores Assistentes da Educação Infantil ao Ensino Médio - rede pública municipal

Os gestores participaram das formações, em seus respectivos horários de trabalho. Contudo, em decorrência do isolamento social imposto pela pandemia, os encontros aconteceram à distância.

Os estudos propostos para os gestores contemplaram as dimensões organizacional/procedimental e conceitual, com a intencionalidade de alinhar as ações propostas pelo projeto formativo ao contexto de cada escola. Para isso, os conteúdos selecionados para os estudos foram: conceitos de valor, conflitos, justiça (regras e sanções), estrutura do PPP (marcos referenciais, diagnóstico e programação) e do Regimento Escolar de cada unidade educativa.

A fim de que os participantes entrassem em contato com os respectivos conteúdos, foram adotadas as seguintes estratégias: leitura de textos sobre valores, os conflitos interpessoais na escola, a perspectiva construtivista sobre os conflitos, PPP, Regimento Escolar e a pesquisa do clima escolar. Em função das aulas dialogadas, fomos sentindo necessidade de narrativas escritas acerca do percurso do trabalho, o que foi registrado progressivamente, em uma narrativa reflexiva, durante todo o projeto formativo. Isso não era apenas uma forma final de registro, mas foi um recurso riquíssimo de produção de dados e de ação-reflexão-ação, em busca do conhecimento possível, para iluminar as hipóteses e a compreensão sobre o que estávamos investigando, dando origem ao projeto investigativo.

Dessa forma, o projeto investigativo se desenvolveu e teve os seguintes objetivos: 
- Conhecer como a comunidade escolar ressignificou os conceitos estruturantes que fundamentam a prática cotidiana;

- Revelar os procedimentos de que o gestor dispõe, para chegar a um projeto de escola que seja político, isto é, participativo e dialógico, capaz de colaborar na direção da satisfação do objetivo.

A produção de dados concretizada durante o projeto formativo foi feita por meio dos chats das plataformas digitais, audiogravações das aulas, atividades executadas pós-aula, as quais foram organizadas e registradas em narrativas. Concordamos com Prado, Soligo e Simas (2014), ao defenderem

[...] que as narrativas ocorridas "no durante", escritas logo após as experiências vividas, seja quando se produz dados, seja nos momentos de registro da pesquisa, o pesquisador coloca-se inevitavelmente em um lugar exotópico (BAKHTIN, 2010). Isto é, para escrever, distancia-se do vivido e, de um outro lugar - e, portanto, com outro olhar - consegue enxergar coisas inalcançáveis.

\section{PROCEDIMENTO DE ANÁLISE DOS DADOS}

Procurando satisfazer aos objetivos da pesquisa do projeto formativo-investigativo, optamos pelo método de Análise de Conteúdo proposto por Bardin (1979), em virtude de ser este um procedimento que pode auxiliar na análise qualitativa dos dados produzidos e de ser, também, considerado adequado ao objeto do presente estudo. As etapas para a realização desse procedimento, segundo essa autora, consistem em: uma fase de pré-análise, da exploração do material e, em seguida, a do tratamento dos resultados, a da inferência e a da interpretação. $\mathrm{Na}$ presente pesquisa, a opção foi pela análise categorial de seus dados, por meio de recortes feitos a partir de produções dos 
gestores participantes das formações. As categorias foram criadas a priori e com base nos módulos-conceitos desenvolvidos durante os estudos - os conceitos de valor, conflito, regras e sanções. Contudo, selecionamos, para este artigo, os dados relativos a valor e a conflito, de sorte a sustentar a hipótese inicial de que o Plano de Convivência Ética, na escola, pode potencializar princípios adormecidos no PPP de uma escola democrática.

$\mathrm{O}$ que dizem os gestores:

O procedimento metodológico para a pré-análise dos dados se deu através das leituras das atividades propostas durante o processo formativo. Nesse momento, com o propósito de investigar, isto é, olhar utilizando "uma lupa" e fazendo uma analogia desse instrumento com a "lente teórica", conversamos e registramos as colaborações dessas duas fontes/vozes: dos pesquisadores/teóricos, os quais fundamentaram as hipóteses de pesquisa, além dos participantes, que relataram suas ideias e práticas. Vamos conhecer esses diálogos. Vale lembrar, como já referenciado por Araújo, Puig e Arantes (2007, p. 95), que “[...] os valores expressos pela instituição são embebidos e se tornam hábitos e atitudes pessoais, conforme são colocados em prática."

Mas, para que os profissionais compreendessem que o valor é o que conservamos como válido, também indicamos a leitura dos tipos de valores: financeiro, estético, moral (MARQUES et al., 2017). Afinal, não é porque é valor que é bom.

Essa foi a metodologia proposta, a fim de que os profissionais construíssem as trocas afetivas necessárias para legitimar as práticas morais, uma vez que valor é uma troca afetiva que o sujeito realiza com o exterior, objetos ou pessoas.

Com a "lupa", sustentamos, teoricamente, que os atores da escola precisam conhecer o PPP e reconhecê-lo como mapa institucional, pois terá impacto em todas as decisões institucionais. Por concordar com os teóricos, sugerimos aos gestores uma busca conceitual nos documentos institucionais: onde estão os valores democráticos que estavam ou deveriam estar aqui? 
Vamos "escutar" o que pensaram acerca do que foi proposto e, através de um olhar indagador, analisaram o que está escrito em seus "mapas" de trabalho.

A atividade a seguir mereceu destaque, porque uma das condições para iniciar um projeto formativo em convivência ética é compreender o conceito de valor. Dessa maneira, os gestores, de sorte a legitimar um determinado conteúdo - projeto na escola -, precisam identificar, dentro da instituição, escutando as pessoas, o porquê e o para quê dessas ações contidas em um projeto.

\section{ATIVIDADE 1 - PÓS-AULA - 22 RELATOS PRODUZIDOS PELOS GESTORES:}

Objetivos: Compreender como as pessoas constroem os valores; distinguir os tipos de valores; reconhecer o tipo de valor dado aos documentos institucionais.

O primeiro conceito estudado foi o de valor. Utilizamos uma analogia com imagens de pastas de documentos sem rótulo, para que pensassem se é possível estabelecer relações sem conhecer dados dos objetos em estudo.

No momento seguinte, quando revelamos mais informações - do tipo: nome dos documentos - PPP 2019 -, o nível da discussão foi ampliado, pois estava aberto o canal para potencializar as contribuições de Cortina (2005), no sentido de explicar que, quando nos deparamos com as coisas, não fazemos apenas operações intelectuais com respeito a elas (compreendemos, classificamos, comparamos; mas, também, nós as apreciamos ou as deixamos de lado).

Partindo dessa premissa, a atividade foi proposta com os seguintes itens: "eu costumava pensar", "Agora penso".

Alguns exemplos de relatos dos participantes:

Eu costumava pensar... que a escola deveria ser um ambiente rico de experiências e propicio para a aprendizagem dos alunos e que os valores deveriam ser aprendidos em casa. 
Agora penso... que escola tem por obrigação trabalhar valores aprendidos ou não em casa. Um lugar onde o aluno deve ser tratado com respeito e amor.

Eu costumava pensar... Apesar de dar voz aos pais, comunidade escolar... talvez eu não pensasse tanto em colocar no PPP as questões dos valores, sejam eles morais, religiosos, culturais, estéticos etc.

Agora penso... que preciso repensar algumas formas de reformular o PPP da escola, colocando mais os pais como protagonistas do processo, procurando outras alternativas para que os mesmos participem mais da elaboração e aprimoramento do referido documento institucional.

Eu costumava pensar... O PPP da escola tem como eixo a construção de valores integrados escola e comunidade em prol da formação global do ser, contribuindo para a construção de indivíduos conscientes e participativos com valores sólidos.

Agora penso que... os valores não é questão de decisão apenas pessoal, os valores são reconstruidos durante as interações do sujeito com o meio, necessitando de instruções necessárias para poder avaliar quais deles seguir, sendo o papel da educação em relação aos valores, oferecer condições de preparar para a apreciação dos que estão relacionados à realização humana e à cidadania, pois, de acordo com o Projeto Político-Pedagógico da escola, considerando o homem como um ser social, é na relação com os seus semelhantes que o ser humano aprende e ensina, se constrói enquanto sujeito e adquire autonomia e valores essenciais para o convivio social, tais como respeito mútuo, solidariedade, afetividade, entre outros.

Nos relatos apresentados, as falas trazem evidências de que, por meio das aulas, das leituras e das discussões, o conceito de valor foi ressignificado pelo gestor. Como revela a afirmação de La Taille ( 2006, p. 75), os valores também podem e devem ser objetos de conhecimento, e a ação moral depende desses conhecimentos. O conhecer não implica fazer, porém, aprimora os nutrientes para a reflexão acerca da influência e da responsabilidade da escola em buscar meios que evidenciem a cultura favorável ao desenvolvimento moral é ético. 
A outra atividade teve a temática da identificação do conceito de conflito nos Marcos Referencais do PPP:

Objetivos: pesquisar o conceito de conflito no PPP e no Regimento Escolar, os quais poderão sustentar as ações do Plano para Convivência Ética na escola.

Das trinta e sete escolas, doze atividades foram analisadas, contudo, apenas quatro apresentam a visão de que o conflito é visto como possibilidade de aprendizagem. Seguem alguns exemplos:

Escola 1: Vale dizer, a democracia dá espaço ao consenso e ao dissenso. Portanto, o conflito entre pessoas é dimensão constitutiva da democracia. O diálogo é um dos principais instrumentos desse sistema. Dialogar pede a capacidade de ouvir o outro e de se fazer entender.

Escola 2: "A criança precisa conviver em confronto com as diferenças" (interação segundo Vygotsky), onde o espaço escolar passa a ser a união das diferentes realidades, ajudando-a a dar significados e um novo olhar para determinadas situações.

Escola 5: Conflitos surgem por opiniões diferentes de algo, e creio que o escutar e buscar uma solução pensando sempre no melhor para os alunos no todo.

A análise revela que as instituições precisam aprofundar a fundamentação teórica a propósito de conflitos, nos documentos que sustentarão o plano de convivência. Ressaltamos que, para se planejar as práticas morais (ou qualquer outra proposta), é necessária a conexão entre a teoria e os procedimentos pedagógicos e encaminhamentos, mediante as intervenções, como estabelecimento de regras e sanções. Dessa forma, a fonte inspiradora estará no conceito de conflito entendido pela instituição: "Que toda pessoa seja movida por investimento afetivo (valores) está claro. Porém, que toda pessoa tenha consciência de quais são esses investimentos não é nada claro." (LA TAILLE, 2006, p. 75).

Se as ações propostas e as decisões ficam conectadas ao pressuposto de que conflito pode ser uma oportunidade de 
aprendizagem para solidariedade e tolerância, concordamos com Tognetta e Vinha (2011, p. 40), quando enfatizam “[...] que a teoria construtivista compreende o conflito e sua resolução como partes importantes do currículo e não apenas como problema a ser administrado."

Destarte, em que local os estudantes, famílias e profissionais podem aprender e exercitar a mediação de conflitos, por meio da fala e da escula(seria escuta?) (diálogo) e da coerência com princípios democráticos, senão na escola?

\section{CONSIDERAÇÕES FINAIS: AS LIÇÕES DESTA PESQUISA}

Este artigo teve como foco buscar satisfazer aos objetivos do projeto formativo-investigativo: conhecer como a comunidade escolar ressignificou os conceitos estruturantes que fundamentam a prática cotidiana, revelar os procedimentos de que o gestor dispõe, para chegar a um projeto de escola que seja político, isto é, participativo e dialógico, capaz de colaborar na direção da satisfação do objetivo. Houve oportunidade, neste texto, de apontar que os objetivos foram alcançados.

É mister considerar, entretanto, que o momento vivido durante as formações, no Caso 2, foi tenso, carregado de expressões que transmitiam ansiedade e medo; a pressão estabelecida entre a carga horária para formação e os conteúdos para o estudo, de certa forma, cooperou igualmente para que houvesse um pouco de estresse também conosco. Isso pode ter sido resultado de o projeto formativo ter sido oferecido de modo virtual; acreditamos que poderia ser muito diferente, se as aulas fossem presenciais e tivéssemos a oportunidade de trabalhos em grupo, quando o grupo estivesse reunido, não de modo on-line, com apresentações e trocas de experiências, durante as aulas e na hora do cafezinho.

Ao reconhecer os avanços que a escola teve, em paralelo ao desenvolvimento do nosso trabalho, naquela instituição, torna-se 
relevante ressaltar que os mantenedores, ao entrarem em contato com a falta de registros para acompanhar os processos, declararam que, “[...] quando o profissional não está mais na escola, não temos como obter informações, pois não houve registro."

Concluiu-se que, ao se perderem algumas características de uma instituição cooperativa - por conseguinte, de uma gestão participativa - chegou-se ao limite institucional de que, sem os valores, não há missão educativa que se sustente! Logo, ao agirem conforme os princípios, diminuíram a heteronomia dos gestores e mantenedores, potencializaram o desenvolvimento da autonomia, por meio da avaliação dos documentos e do diálogo como ferramenta ética.

Dessa forma, reconheceram a estrutura do PPP e a sua funcionalidade, na gestão democrática; identificaram o conceito de valor e de conflito; constataram os valores institucionais descritos no PPP.

É notório que é responsabilidade do gestor atuar em prol da gestão democrática, e isso não é negociável; portanto, por intermédio dos registros dos procedimentos escolares - significados compartilhados -, a comunidade pode analisar diagnósticos, propor ações e acompanhá-las, a fim de transformar o que for possível.

No Caso 2, em razão dos estudos proporcionados pelo Projeto Convivência Ética na Escola, muitas ações foram vivenciadas nas escolas da rede municipal e discutidas nos encontros, nos estudos com gestores, estando o foco nos objetivos do projeto formativo-investigativo: conhecer como a comunidade escolar ressignificou os conceitos estruturantes os quais fundamentam a prática cotidiana, revelar os procedimentos de que o gestor dispõe, para chegar a um projeto de escola que seja político, isto é, participativo e dialógico, capaz de colaborar na direção da satisfação do objetivo.

Embora tenhamos tido resultados otimistas e os objetivos satisfeitos, a realidade mostra que não são suficientes para que 
haja transformação na rede, se não houver a implicação de toda a comunidade e de cada escola.

Podemos concluir que, se os gestores das escolas sabem o que querem, para onde desejam ir, e por onde caminharão - PPP, os valores sociomorais e o conceito de conflito serão o aporte necessário às oportunidades de aprendizagem e ao desenvolvimento das habilidades para uma convivência respeitosa e justa, ou seja, os conceitos que estão nos livros e nos documentos oficiais poderão se transformar em alternativas e possibilidades para os atores revelarem, por meio das ações, o que ficou internalizado como valor para agir, isto é, o que ficou legitimado. Vale lembrar que sem responsabilidade não há ética, assim como sem respeito não há moral.

Ora, entendemos que a responsabilidade em aprender não é somente do aluno, e o presente trabalho busca apresentar ao gestor alternativas de ações que possibilitam categorizar diferentes áreas de atuação, orientando o estudo da realidade escolar para o alcance das expectativas traçadas nos objetivos da instituição. Se ao professor cabe o domínio do conteúdo e a metodologia, o gestor deve estar incumbido do domínio de indicadores da gestão. A finalidade é envolver a comunidade e afetá-la, no sentido de querer fazer para o bem comum. Trata-se de pautar a cultura da convivência e do trabalho escolar em valores morais e não somente em prazos de entrega e planos que se distanciam da função política de uma educação comprometida com o desenvolvimento da autonomia.

Mesmo com tantos ajustes, a análise foi positiva e esperamos que esta pesquisa possa contribuir como inspiração para outros formadores, os quais possam investigar sua própria prática.

\section{REFERÊNCIAS}

ARAÚJO, U. F.; PUIG, J. M.; ARANTES, V. A. (Org.). Educação e valores: pontos e contrapontos. Coleção Pontos e Contrapontos. São Paulo: Summus, 2007. 
BARDIN, L. Análise de conteúdo. 70. Ed. Lisboa. 1979.

CORTINA, A. Cidadãos do mundo. Para uma teoria da cidadania. São Paulo: Loyola. 2005.

LA TAILLE, Y. de Moral e ética: dimensões intelectuais e afetivas. Porto Alegre: Artmed. 2006.

MARQUES, C. A. E. et al. Valores Sociomorais. Coleção Valores Sociomorais. Americana: Adonis. 2017.

QUALIDADE. Manual para o Diagnóstico Institucional e o desenho do Plano de Melhoramento. Chile: Fundação Chile, 2009.

PRADO, G. V.; SOLIGO, R.; SIMAS, V. F. Pesquisa narrativa em três dimensões. In: CIPA - CONGRESSO INTERNACIONAL DE PESQUISA (AUTO) BIOGRÁfICA, VI., Modos de Viver, Narrar e Guardar. Rio de Janeiro, 2014.

TOGNETTA, L. R. P. A formação da personalidade ética: estratégia de trabalho com afetividade na escola. Campinas. Mercado de Letras. 2009.

TOGNETTA L. R. P.; VINHA, T. P. Quando a escola é democrática: um olhar sobre a prática de regras e assembleias na escola. Campinas: Mercado de Letras, 2011.

VASCONCELLOS, C. S. Planejamento - Projeto de Ensino-Aprendizagem e Projeto Político-Pedagógico. São Paulo: Liberdade, 2012.

VASQUEZ, A. S. Ética. 14. ed. Rio de Janeiro: Civilização Brasileira, 1993. 